\title{
DISCUSSIONS
}

\section{IN DEFENCE OF OBJECT-DEPENDENT THOUGHTS}

\author{
by Sean Crawford
}

ABSTRACT The existence of object-dependent thoughts has been doubted on the grounds that reference to such thoughts is unnecessary or 'redundant' in the psychological explanation of intentional action. This paper argues to the contrary that reference to object-dependent thoughts is necessary to the proper psychological explanation of intentional action upon objects. Section I sets out the argument for the alleged explanatory redundancy of object-dependent thoughts; an argument which turns on the coherence of an alternative 'dual-component' model of explanation. Section II rebuts this argument by showing the dualcomponent model to be incoherent precisely because of its exclusion of object-dependent thoughts. Section III concludes with a conjecture about the further possible significance of object-dependent thoughts for the prediction of action.

$\mathrm{O}$

bject-dependent thoughts are thoughts about particular objects to which the thinker stands in some kind of special relation of acquaintance and that are such that they would not be available to be thought if those objects did not exist. The very existence and identity of an object-dependent thought depends upon the existence and identity of the objects it is about. ${ }^{1}$ The aim of this paper is to defend the thesis that

A satisfactory psychological explanation of an agent's intentional action upon an object must make reference to object-dependent thoughts of the agent involving the given object acted upon. ${ }^{2}$

and to rebut a recent anti-externalist argument whose conclusion is that this thesis is false.

The Necessity Thesis, or Thesis $\mathbf{N}$, as I shall call it, has recently come under attack by a number of internalistically-minded philosophers. Harold Noonan, for example, seeks to defend the following contrary claim:

1. See Gareth Evans, The Varieties of Reference (Oxford: Clarendon Press, 1982); John McDowell, 'De Re Senses', in C. Wright (ed.), Frege: Tradition and Influence (Oxford: Basil Blackwell, 1984); John McDowell, 'Singular Thought and the Extent of Inner Space', in P. Pettit and J. McDowell (eds.), Subject, Thought, and Context (Oxford: Clarendon Press, 1986).

2. Cf. Christopher Peacocke's 'Indispensability Thesis' in his 'Demonstrative Thought and Psychological Explanation', Synthese 49 (1981), a paper to which I am indebted. I have also been influenced by the ideas that Terrance Tomkow presented in lectures at Dalhousie University in 1992/93. 
Whenever an action is directed towards a concrete, contingently existing object, other than its agent, in the sense that it is intentional under a description in which there occurs a singular term denoting that object, then an adequate psychological explanation of it is available under a (possibly distinct) description in which occurs a term denoting that object; and in this explanation the only psychological states of the agent referred to are ones which would also be present in a counterfactual situation in which the object did not exist. ${ }^{3}$

He calls this claim the Redundancy Thesis (or Thesis $\mathbf{R}$ for short), because it claims that object-dependent thoughts are redundant in the explanation of action. Notice that what $\mathbf{N}$ claims is always true $\mathbf{R}$ claims is never true. That is, $\mathbf{N}$ claims that it is always necessary to attribute object-dependent thoughts to an agent to explain his action upon an object; $\mathbf{R}$, in contrast, claims that it is never necessary to do so. With a view to resolving this dispute in favour of $\mathbf{N}$ let us turn first to the argument for $\mathbf{R}$.

It will help to furnish ourselves with a typical twin example. The ubiquitous Ralph reaches out for a glass of lemonade on the kitchen counter. Why? Well, for a start, he has just come in from mowing the lawn on a hot summer day and so desires a thirst-quenching beverage and thinks to himself that lemonade is thirst-quenching. Meanwhile, over yonder, Twin Ralph, who is Ralph's doppelgänger, also reaches out in an attempt to grasp a glass of lemonade which is not there-for Twin Ralph is hallucinating a glass of lemonade.

The challenge to those who would defend Thesis $\mathbf{N}$ is to give an intentional psychological explanation for Twin Ralph's behaviour without attributing to him any object-dependent thoughts. Here we allegedly face an unwelcome dilemma. Either Twin Ralph's behaviour is rationally explicable or it is not. Suppose that it is not. This is an unacceptable consequence of the doctrine of object-dependent thought because deluded Twin Ralph does act rationally, and hence, his behaviour should be intentionally explicable. ${ }^{4}$ Suppose, on the other hand, that Twin Ralph's behaviour is explicable in terms of psychological states none of which include object-dependent thoughts. If this is so, then the behaviour of non-deluded Ralph should be equally explainable without attributing

3. 'Russellian Thoughts and Methodological Solipsism', in J. Butterfield, ed., Language, Mind and Logic (Cambridge: CUP, 1986), pp. 68-69; my emphasis. Unadorned references in the text are to this work. See also Noonan's 'Object-Dependent Thoughts and Psychological Redundancy', Analysis 51 (1991), cited as ODT. Essentially the same position and argument for it can be found in Gabriel Segal, 'The Return of the Individual', Mind xcviii (1989). Cf. Peter Carruthers, 'Russellian Thoughts', Mind xcvi (1987). 
to him object-dependent thoughts. Why does this follow? Well, Twin Ralph has a set of beliefs and desires that constitute a sufficient reason for reaching out. Call this set ' $X$ '. Since Ralph is Twin Ralph's twin he has all of Twin Ralph's beliefs and desires and possibly some extra ones as well (namely, those object-dependent ones if there any such things); that is to say, he too has X. In other words, $\mathrm{X}$ is a subset of Ralph's thoughts. But $X$ is sufficient reason for a subject to reach out-which is just what Ralph did. So X is sufficient to explain Ralph's behaviour as well as Twin Ralph's. So the 'extra' object-dependent thoughts that Ralph allegedly has are redundant in explaining his action.

The obvious objection to this argument is that the Ralphs do not do the same thing. For Ralph really does reach out for a glass of lemonade while Twin Ralph does not. Invoking Quine's relational idiom of attitude attribution, we can say that, in Ralph's case, a glass of lemonade is acted upon by him but no glass of lemonade is acted upon by Twin Ralph. ${ }^{5}$ The objection is that object-dependent thoughts are not redundant in explaining the action of Ralph relationally described. So the idea is that since $\mathrm{X}$ is the set of thoughts that explain deluded Twin Ralph's behaviour, it is not adequate to explain non-deluded Ralph's action relationally described. It is X plus some object-dependent singular thoughts that explains Ralph's actions vis-a-vis the glass of lemonade.

To this objection the defender of Thesis $\mathbf{R}$ replies that while it is true that X alone cannot explain Ralph's action relationally described, X combined with mention of his environment can. That is, $\mathrm{X}$ together with the fact that there is a glass of lemonade in the offing, ensuring the truth of

4. That Twin Ralph does act rationally is in fact a much more contentious claim than the advocate of Thesis $\mathbf{R}$ allows. Space limitations prevent me from discussing the interesting question of whether such pure hallucinators act rationally and, if so, given the multifarious meanings of 'rational', which sense of the term is being employed. Perhaps a few words are in order, however. One salient sense of 'rational' is that an agent acts rationally if there is a practical syllogism available to rationalize his behaviour. However, given that the anti-objectdependent theorists I am responding to (especially Segal, op. cit.) seem committed to the view that the empty demonstrative thoughts of the pure hallucinator do not have truth conditions it is hard to see how they could figure as premises in a practical syllogism from which an agent could reason. Segal, e.g., follows Tyler Burge and Kent Bach in holding that such thoughts have the same kind of content as open sentences; what is unclear, however, is whether he follows Burge in advocating a free logic in which empty token applications of predicates come out false, or Bach in advocating the view that such token applications simply lack truth conditions. For details see Burge, 'Russell's Problem and Intentional Identity', in James Tomberlin, ed., Agent, Language, and the Structure of the World (Hackett, 1983) and Kent Bach, 'De Re Belief and Methodological Solipsism', in Andrew Woodfield, ed., Thought and Object (Oxford: Clarendon Press, 1982). The upshot is twofold: more work needs to be done to show, first, that impalement on the first horn of the dilemma is such a bad thing, and second, that anti-object-dependent theorists are themselves entitled to the claim that the pure hallucinator acts rationally.

5. For the distinction between relational and notional attributions see W. V. Quine, 'Quantifiers and Propositional Attitudes', reprinted in his Ways of Paradox and other Essays (New York: Random House, 1966). 
the relational description, explains Ralph's action. I shall call this the dualcomponent (D-C) conception of relational psychological explanation because it invokes two components: a purely psychological component and a non-psychological component. ${ }^{6}$ So even under a relational description, there is still no need to cite object-dependent thoughts to explain actions.

\section{II}

The problem with the dual-component reply to the objection from relational characterization is that one of its key assumptions is false: namely, the claim that 'an adequate psychological explanation of an action under a non-relational description, together with a description of the surrounding circumstances in which that action constitutes an action answering to some relational description, provides an adequate psychological explanation of it under the relational description' (ODT, p. 4). That is to say, it is simply not true that X supplemented with a description of Ralph's surroundings-namely, that there was a glass of lemonade so located that Ralph made contact with it-is an adequate explanation of Ralph's behaviour vis-a-vis the lemonade.

To see this, consider the possible situation in which Ralph hallucinates a glass of lemonade on the counter and, luckily, there also happens to be a glass of lemonade on the counter matching the hallucinatory content and so positioned that, although Ralph does not perceive it, he grasps it. The tu quoque challenge to the dual-component theorist is to explain Ralph's action (relationally described) in this situation in a way that does not imply that he did the same thing (relationally described) as the Ralph in the normal situation, that is, that does not imply that he intentionally, that is, deliberately, grasped the glass. It seems reasonable to think that the explanation of an action in such a case of 'veridical hallucination' should be different from the explanation of action in the normal veridical case. This is so because the actions are different: Ralph intentionally grasps the glass of lemonade whereas Lucky Ralph, as I will call him, does not.

The key question, then, is: Can the D-C model distinguish the two cases? It would seem not. For consider what the D-C explanation of Lucky Ralph's action of (unintentionally) grasping the glass will be. It will presumably consist in the citation of X (for, by hypothesis, Lucky Ralph's thoughts are also a subset of Ralph's thoughts) and the fact that there was a glass in the offing. But this is the same explanation that the D-C conception gives of Ralph's action of intentionally grasping the glass. But Ralph and Lucky Ralph do different things and so presumably their behaviour should not be given the same explanation. So the D-C conception is not a correct account of relational explanation. What is

6. It is endorsed by Noonan, Segal, and Carruthers. 
missing from the account is Ralph's intending, of the lemonade, that he grasp it. The most that the dual-component conception can explain is Ralph's action relationally described as his picking up that glass of lemonade. It cannot explain his action relationally described as his intentionally picking up that glass of lemonade.

Noonan is aware of the threat that cases of veridical hallucination pose for the D-C model. Unfortunately, he misdiagnoses the nature of the threat and thus his response falls far short of dealing with the real problem. Noonan sees the asymmetry between the two cases of Ralph and Lucky Ralph as one where Lucky Ralph's grasping the glass is a coincidence whereas Ralph's is not. This seems to be a problem because there is a sense in which coincidences have no explanation and so unlike Ralph, Lucky Ralph's behaviour should, in a sense, be inexplicable. The D-C theorist, however, seems committed not only to the explicability of Lucky Ralph's behaviour but also to its being explicable in exactly the same way as Ralph's behaviour. Noonan, however, 'wish[es] to explain the intuitive difference between the two cases by reference to the difference between knowledge and (accidentally) true belief' (ODT, p. 7). The idea is that since Ralph knows that there is a glass in front of him his grasping it is no coincidence; whereas since Lucky Ralph has a merely accidentally true belief it is a coincidence that he grasps the glass. 'But if this is the explanation of the intuitive difference between the two cases', Noonan concludes, 'then since knowledge and belief can have the very same content, nothing in the set-up requires us to say that some objectdependent psychological states had by non-deluded [Ralph] are essential to the adequate psychological explanation of his action' (Ibid.).

Two things can be said in response to this appeal to the distinction between knowledge and accidentally true belief. First of all, with a bit of Gettier-style stage-setting the example can be rigged so that it is not a coincidence that there is an object matching the hallucinatory content of Lucky Ralph's thought. We merely need to imagine that either the object itself is the cause of the matching hallucination or both the presence of the object and the matching hallucination have a common cause. In both versions it will true that if the object had not been there then the hallucination would not have occurred. Though I omit the fine details, the nature of such admittedly bizarre examples is familiar from the literature on the causal theory of perception and perceptual knowledge. In such an augmented version of Lucky Ralph's story it is not a coincidence that he grasps a glass of lemonade (and so he is not really lucky) and so his belief that there is a glass of lemonade in front of him is not accidentally true; there is a perfectly good explanation of why his belief is true. Moreover, according to some externalist accounts of knowledge, in the augmented version of the story Lucky Ralph does know that there is a glass in front 
of him. ${ }^{7}$ No doubt there are also accounts of knowledge according to which Lucky Ralph does not know there is a glass in front of him. So, at the end of the day, this appeal to knowledge has the consequence of shifting into the domain of epistemology the debate over whether the Ralphs do the same thing and whether their actions should be given the same explanation. Fortunately, as we shall shortly see, a resolution of this puzzle does not await the arrival of the correct theory of knowledge.

The second point is that even in the original unaugmented version the distinction between Ralph's knowledge and Lucky Ralph's accidentally true belief does not secure a relevant difference between the two cases. For recall that the knowledge reply to the example of veridical hallucination turns essentially on the correct claim that knowledge and belief can have the same intentional content. Notice, however, that since, by hypothesis, Lucky Ralph does not perceive the glass in front of him, the content of his accidentally true belief cannot be demonstrativewhether or not demonstrative thoughts are object-dependent; rather, it must be an existentially quantified content such as that there is $a$ glass in front of him. Indeed, it may already have been noticed that what Noonan says that Ralph knows is that there is a glass in front of him. But Noonan cannot appeal to such a shared existentially quantified content to explain the Ralphs' actions for he agrees with his opponents that the explanation of at least certain kinds of action upon objects does require the attribution of demonstrative thoughts-his point is that demonstrative thoughts are not object-dependent. ${ }^{8}$ So it is agreed on all sides that it is a shared demonstrative content that is needed to explain the Ralphs' actions-or, at least there will be cases where this is true; but the knowledge reply offers only an existential content and so fails to secure the needed distinction between the intentional explanations of what the Ralphs did.

In any case, it seems to me that coincidence is not the intuitive difference between the two cases; or rather, even if it is a difference it is not the deepest difference. For the source of the coincidence lies, not in a lack of knowledge, but in the absence of intention. The reason that Lucky Ralph only coincidentally picks up the glass in front of him is not that it is an accident that there happens to be a glass in front of him; rather, it is a coincidence because he did not intend to pick up that glass. The distinction between knowledge and accidentally true belief does not secure a distinction between intending to pick up that glass of lemonade and accidentally picking it up.

7. See, e.g., Robert Nozick, Philosophical Explanations (Oxford: Clarendon Press, 1981), p. 190.

8. I should emphasize that my criticisms are directed at those theorists-e.g., Burge, Bach, Segal, Noonan, and Carruthers - who agree that demonstrative thoughts are not reducible to descriptive thoughts. 
What more than the set $\mathrm{X}$ and the fact that there is a glass of lemonade in front of him is needed to ensure that Ralph picks it up intentionally? Obviously Ralph has to intend to pick it up. But what is it for Ralph to intend to pick it up? What does Ralph have that Lucky Ralph does not have which allows us to say that he intentionally picked up the glass? We have seen that knowledge of the purely existential fact that there is a glass in front of him does not allow us to say that Ralph intentionally picked up that glass. In the absence of any other candidates, I submit that it is the fact that Ralph has object-dependent demonstrative thoughts about the glass of lemonade whereas Lucky Ralph does not. That is to say, for example, Ralph desires to drink that glass of lemonade; Ralph believes that that glass of lemonade will be thirst-quenching; believes that his wife set it out for him to drink, that it is his favourite glass... etc. None of this is true of Lucky Ralph: he has no thoughts at all about the glass of lemonade. ${ }^{9}$ The reason for this is clear: he does not perceive the glass. This is just a particular instance of what I would conjecture is a general thesis: namely, that a necessary condition for an agent to act intentionally upon an object is that the agent have some object-dependent thoughts about that object. I think it is this thesis that drives the lurking suspicion that reference to $X$ and the mere presence of a glass in the offing falls short of providing a satisfactory explanation of Ralph's intentional action $v i s-a$-vis the glass. The dual-component conception seems to drain away the genuine agency of individuals.

The D-C model suffers further related defeats as well, as can be illustrated by the following case. Unbeknownst to Ralph, his wife is trying to kill him and has put some poison in his lemonade. Poor thirsty Ralph swills down the poison. His action can now be relationally described as the imbibing of poison. How do we explain his action thus relationally characterized according to the D-C conception? Well, we say that Ralph had $\mathrm{X}$ and the poison was strategically - or rather, tragically-positioned in his environment. These two facts suffice to explain Ralph's action relationally so characterized. Of course, Ralph did not intend to imbibe the, or indeed any, poison. But he did intend to drink the lemonade. This points out the fact that the important difference between the actions of Ralph and Twin Ralph is not merely the fact that the former's action can be described relationally in terms of the presence of a glass while the latter's cannot. For Ralph's action can be given any number of relational descriptions that Twin Ralph's cannot-but not all of these relational descriptions are the relevant explanandum of a psychological explanation

9. At least not until the moment when he grasps the glass. Or, if his hallucination persists even after that moment and is multi-modal, then he has no object-dependent thoughts until his hallucination subsides. 
of intentional action. ${ }^{10}$ There is a further constraint on what relational descriptions are relevant: they must be ones that the agent would recognize as descriptions of his intended action. But since the singular term designating the object acted upon in the second environmental component of the D-C explanation occurs in transparent position, because it falls outside the scope of the agent's psychological attitude, it is hard to see how the D-C model can meet this constraint. While the D-C conception can explain relational facts such as that Ralph unintentionally imbibed poison, it appears powerless to explain certain other relational facts such as that Ralph intentionally drank the lemonade. Unfortunately for the D-C conception, what is needed to explain these latter type of relational facts are object-dependent thoughts. But since none of these object-dependent thoughts will appear in the subset X, it plus additional environmental factors are insufficient to explain Ralph's action of intentionally picking up the glass of lemonade and drinking it.

Turning to another shortcoming of the D-C model, it is pretty clear that what makes Ralph's action an intentional reaching for a glass of lemonade is not, as Noonan claims, 'simply' the presence of the lemonade (ODT, p. 4) or, as Gabriel Segal puts it, the fact that the lemonade 'is around' ( $p$. 45 ), so that the bodily movements brought about by X can be described relationally. The lemonade must also causally affect him in some way. Or rather, in the situation as it actually happened, it was the lemonade's causally affecting Ralph that caused him to form the intention of drinking it. It follows from this that if there had been no lemonade then Ralph would not have reached out as he did. Given Ralph's antecedent desire for a thirst-quenching beverage, it also follows that if the glass of lemonade had been on the other counter then Ralph would have moved towards that counter instead. Or if there had been a glass of cider on the counter then Ralph still would have reached out in the way he did (given that he has the appropriate general beliefs about cider).

The general point we are converging on, of course, is that psychological explanations, like all causal explanations, support counterfactuals. But the dual-component explanation of Ralph's action, as stated by the defenders of Thesis R, fails to sustain the relevant counterfactuals. Recall that on the D-C conception Ralph moves the way he does because of that subset of this thoughts, X, that he shares with Twin Ralph. The additional environmental factor of the presence of the lemonade is thrown in so as to ensure that we can describe his bodily movements relationally. But if all that is causing Ralph to move his body in the manner in which he does is $\mathrm{X}$ then

10. If I understand him aright, this is another way of putting Christopher Peacocke's point, in 'Externalist Explanation', Proceedings of the Aristotelian Society XCII (1993), that 'Quite generally, explanation of a truth by a given set of states is not preserved by substitution of coextensive predicates in that truth' (p. 208). 
it follows that he might have done so whether or not the lemonade was present. To counter this absurd consequence, the D-C explanation must, as Christopher Peacocke notes, be 'supplemented with a batch of specifications of the external relations in which bodily movements would have stood under various different external antecedent conditions' (p. 208) and 'as we add more and more relational specifications to the original explanation involving only an internalist state, the question arises of whether we are not in fact adding sufficient material to ensure that the subject is, after all, in an externalist state' (p. 209). The question arises, moreover, as to whether such a batch of supplementary specifications is not sufficient to ensure that the subject is no longer in a psychological state that is shared by his hallucinating doppelgänger.

\section{III}

I turn finally and very briefly to the rather different point that objectdependent thoughts have a further utility which can be brought out by switching to consideration of the prediction of action. The idea I have in mind is that knowing which object-dependent thoughts an agent has allows us to predict which object he will in fact act on. So the question I wish to close with is whether we can predict which object an agent will act upon-that is, what the agent will in fact do-without the help of object-dependent thought attributions. Is reference to object-dependent thoughts also redundant in the prediction of action?

Suppose Ralph goes into the kitchen in quest of a glass of lemonade. As it happens there is also a glass of gin and tonic on the counter next to the glass of lemonade. Let us imagine what a D-C style prediction of Ralph's behaviour would look like. Suppose, for example, what the defenders of Thesis $\mathbf{R}$ do suppose, that the set $\mathrm{X}$ can contain demonstrative thoughts, such as wanting to drink that glass of lemonade, even in the absence of an object for them to be about. ${ }^{11}$ Such an attribution is not existentially committing: it does not license the Quinean relational attribution that the glass of lemonade is such that Ralph wants to drink it; so it is a belief that deluded Twin Ralph could also have. Does knowing that Ralph wants to drink that glass of lemonade, where this is an attribution of an object-independent demonstrative thought, enable us to predict that Ralph will reach out for the glass of lemonade? Not unless it is in fact the glass of lemonade that is believed by Ralph to be the glass of lemonade. If it is the gin and tonic that is mistakenly believed by Ralph to be the glass of lemonade then it is the gin and tonic that he will reach out for and not the glass of lemonade. Since such object-independent

11. For reasons given in footnote $8 \mathrm{I}$ set aside descriptive thoughts. 
demonstrative thoughts do not entail the truth of any relational attribution, we can always ask the question: Which object is it that is believed by Ralph to be that glass? Until we know the answer to this question we will not be in a position to predict which object Ralph will act upon.

I conclude, then, against the Redundancy Thesis, that far from being redundant in the explanation and prediction of action upon objects, reference to object-dependent thoughts plays an essential role in such endeavours. The Necessity Thesis stands fast. 12

Exeter College

Oxford OX1 3DP

email: sean.crawford@philosophy.ox.ac.uk

12. Thanks to Sarah Sawyer, Rowland Stout, Galen Strawson, audiences at Sheffield University and Oxford University's Wolfson Society, and especially Martin Davies and Elizabeth Fricker for very helpful comments on earlier versions of this paper. 